\title{
A Study on the Logistics Information Synchronization based Smart SCM Model
}

\author{
JangGoon. $\mathrm{Kim}^{+}$
}

\begin{abstract}
Recently, there have been many studies on RFID-based SCM. Yet, studies of synchronizing errors caused by tracking logistics information in supply chain, and activating \& monitoring RFID infra is still insufficient. Also, there is no case of developing the intelligent SCM system enabling total monitoring and controlling RFID Infra by applying these technologies.

Logistics information synchronization based Smart SCM model is intelligent supply chain service model to monitor the status of the RFID equipments in supply chain and the synchronization of the logistics process in each logistics point through one integrated view, as well as to react instantly by providing the information to help the various decision makings, when the emergency occurs. By adopting global logistics standard, RFID related standard specification, EPCIS standard, and SSI middleware platform, this model provides the domestic standard specification.
\end{abstract}

\footnotetext{
Keywords : RFID(Radio Frequency IDentification), EPCIS(Electronic Product Code Information Service), SSI(Software System Infrastructure)
}

\section{물류정보동기화 기반의 Smart SCM 모델에 관한 연구}

\author{
김 장 군 $^{+}$
}

요 약

\begin{abstract}
최근들어 $\mathrm{RFID}$ 기반의 $\mathrm{SCM}$ 에 대한 연구는 많이 진행되고 있다. 그러나 공급망상에서 이동중인 물류정보의 오류를 동기화하고, 장치기반 인프라의 상태정보를 모니터링하여 활성화해주는 연구와 기술은 아직 미흡하다. 또한 이를 응용하여 통합관제해주는 지능형 $\mathrm{SCM}$ 시스템을 개 발한 경우는 없었다.

「물류정보동기화 기반의 Smart SCM 모델」은 실시간으로 각 물류 거점에 설치된 RFID 인프라 장치 및 물류 프로세스 동기화 현황을 하 나의 통합된 뷰를 통하여 모니터링하고, 예외상황 발생시에 다양한 의사결정 지원정보 제공을 통해 즉각적인 상황 조치가 가능한 지능형 공급 망 통합관제 서비스 모델이다. 본 연구 모델은 물류국제 표준, RFID관련 국제 표준 규격, $\mathrm{EPCIS} \mathrm{표준,} \mathrm{SSI} \mathrm{미들웨어} \mathrm{플랫폼을} \mathrm{준용하여} \mathrm{표준}$ 화 하므로써 관련 기술 국내 표준 규격을 제시하고자 하였다.
\end{abstract}

키워드 : 무선주파수인식기술, 물류정보동기화, 동기오류

\section{1. 서 론}

세계 경제는 정보기술 확산단계에서 정보기술를 활용한 생산성 향상 및 경쟁력 강화를 위한 정보기술 활용 고도화 단계로 진행중이다. 국제무역의 형태가 글로벌화 되면서, 신

※ 이 논문은 한국정보처리학회 제 38 회 추계학술발표대회에서 '물류정보동기화 기반의 Smart $\mathrm{SCM}$ 모델에 관한 연구'의 제목으로 발표된 논문을 확장한 것임.

※ 본 논문은 지식경제부의 지원으로 $\mathrm{LG}$ 히다찌가 수행하고 있는 $\mathrm{r}$ 고신뢰성 글로벌 물류정보 동기화 기술개발 사업의 결과물임.

† 정 회 원: $\mathrm{LG}$ 히다찌 솔루션서비스본부 전문위원

논문접수: 2012년 12월 24일

수 정 일 : 1 차 2013년 1월 11일

심사완료: 2013년 1월 11일

* Corresponding Author: JangGoon. Kim(legend7080@gmail.com)
속한 국제물류 프로세스의 효율화를 위하여 인식기술에 기반 한 RFID(Radio Frequency IDentification, 무선인식기술)를 활용한 다양한 기술 적용이 시도되고 있다. 현재 각 산업의 제품생산과 유통단계에 적용되고 있는 RFID 기술은 물류정 보와 연계되어 물류의 추적성(Traceability), 가시성 (Visibility), 이동성(Mobility)을 크게 향상시킬 수 있다[1]. 이는 화물 및 물류의 가시성이 중요하게 부각되고 있는 오늘 날의 $\operatorname{SCM}$ (공급망관리, Supply Chain Management)에서도 이러한 RFID의 활용에 대한 필요성이 더욱 증가하고 있는 추세이다[2]. 그러나, 원격지에 구축된 $\mathrm{RFID}$ 를 비롯한 $\mathrm{u}^{-}$ $\mathrm{SCM}$ 장비 및 시스템에 대한 유지보수 등이 적절하게 이뤄 지지 못해 직간접적인 피해를 입고 있는 실정이다. 실제로 
물류와 시스템 상의 물류정보 간 동기화 오류로 인해 세계적 으로 연간 판매기회 손실액이 219조원에 이르고 있다[3].

또한, 2009년 호주 Wollongong 대학의 비즈니스 서비스 과학 센터에서 조사 발표한 'RFID Adoption'에서는 RFID를 도입한 기업의 가장 중요한 성공전략 요소로 물류데이터 정 확성을 꼽은바 있다.

본 연구는 공급망 현장의 무인 거점에 구축된 $\mathrm{RFID}$ 하드 웨어, 소프트웨어 시스템과 $\mathrm{SCM}$ 상의 다자간 물류 프로세스 를 실시간으로 모니터링하여, RFID 인프라 설비 및 물류 프 로세스의 장애나 이상 상태에 의해 발생한 물류정보 오류를 조기에 검출하고 복구하는 관제 기술 개발을 목표로 하였 다. 또한, 「물류정보동기화 기반의 Smart SCM (약자 $\mathrm{SSCM}$ ) 모델」에서는 공급망관리에 $\mathrm{RFID}$ 기술 적용의 신 뢰성을 확보하기 위하여 EPCglobal과 $\mathrm{ISO} / \mathrm{IEC}$ 의 $\mathrm{RFID}$ 기 술 및 표준자료[4][5][6]를 수집하여 $\mathrm{SSCM}$ 모델 설계시에 표준으로 반영하고자 하였다.

\section{2. 표준화 및 기술 동향}

\subsection{RFID 기술 표준화 동향}

최근 국제표준화 기구인 $\mathrm{ISO}$ 에서는 관련 통신규약, 식별 코드, 성능시험 방법 등 대부분의 기술표준 제정을 완료하 였으며, 한국은 $\mathrm{ISO}$ 규격 26 종을 $\mathrm{KS}$ 규격으로 제정하였다. 또한 컨테이너 보안용 $\mathrm{e}-\mathrm{Seal}, \mathrm{SCM}$ 등의 응용표준 등은 여 러 실증 시험을 거쳐 완성단계에 있다.

1) RFID 국제 표준화 기구

$\mathrm{RFID}$ 관련 국제 표준은 태그 및 리더 등 RFID 기기에 대한 표준과 RFID 태그에 저장되는 식별 코드 표준으로 크 게 구분할 수 있다. 코드의 경우 다른 코드는 응용 분야가 제한적인 경우가 많으나 EPCglobal이 보급하고 있는 $\mathrm{EPC}($ Electronic Product Code) 코드는 유통 - 물류를 중심으 로 전체산업에 적용 가능하며, 이미 바코드와 함께 산업계 에서 널리 이용되고 있는 $\mathrm{EAN} \cdot \mathrm{UCC}$ 식별 코드도 $\mathrm{EPC}$ 코 드에서 수용 가능하도록 표준이 제정되어 있다.

$\mathrm{RFID}$ 의 국제 표준화는 $\mathrm{ISO}$ 와 $\mathrm{IEC}$ 가 공동으로 구성한 $\mathrm{ISO} / \mathrm{IEC} \mathrm{JTC1}$ 산하 $\mathrm{SC} 31 \mathrm{WG} 4$ 가 중심이 되어 추진된다. $\mathrm{RFID}$ 태그와 안테나 간의 에어 인터페이스(air interface) 또는 프로토콜 등의 국제표준은 $\mathrm{ISO}$ 의 데이터 인식기술 분 과위원회(JTC/SC31)에서 추진중이다[7].

a) ISO/IEC JTC1 SC31 WG4

전통적인 유통, 물류 등 기업응용분야의 RFID 기술에 대 한 국제표준을 개발하고 있다.

- SG1 : 응용 시스템 인터페이스 표준화

- SG3 : 무선접속 인터페이스 표준화

- SG5 : 시스템 구현 및 요구사항 표준화

b) EPCglobal

$\mathrm{JTC} 1 / \mathrm{SC} 31 / \mathrm{WG} 4$ 와 같이 유통, 물류 등 기업응용분야의
$\mathrm{RFID}$ 기술에 대한 시장표준을 개발한다.

c) ITU-T TSAG JCA-NID

$\mathrm{ITU}-\mathrm{T}$ 의 각 $\mathrm{SG}$ 를 총괄하는 자문그룹으로서 ITU-T 및 타 표준화 기구와의 표준화 역할, 내용 조율 등 협력을 추 진한다.

d) ASTAP NID EG

아.태 지역의 국제표준화 동향을 파악하고 협력한다.

e) CJK N-ID WG 표준기구

한.중·일 간 RFID 사업 및 표준화 협력을 추진한다.

2) RFID 표준화 현황

a) 국제 표준화 현황

$\mathrm{EPC}$ 보급에 앞장서고 있는 국제단체인 EPCglobal은 $\mathrm{SCM}$ 상의 모든 주체들에 $\mathrm{RFID}$ 를 적용하여 유용한 정보들 을 서로 공유할 수 있도록 하는 EPCglobal N/W 구축을 완 료하고 업종별 비즈니스 모델 발굴을 위해 유통 - 물류및 의 류, 약품 분야 등에 액션 그룹을 운영하고있다[9].

Table 1. Standardization of the EPCglobal Network

\begin{tabular}{|c|c|c|c|}
\hline Bounds & Standard & State & Time \\
\hline \multirow{4}{*}{$\begin{array}{c}\text { Object } \\
\text { Exchange }\end{array}$} & UHF Class 0 Gen 1 RF & & 2003.02 \\
\cline { 2 - 2 } & UHF Class 1 Gen 1 RF & \multirow{4}{*}{ Ver. 1.09 } & 2002.11 \\
\cline { 2 - 2 } & HF Class 1 Gen 1 Tag & & 2003.02 \\
\cline { 2 - 2 } & HF Class 1 Gen 2 Tag & & 2005.01 \\
\cline { 2 - 4 } & EPC Tag Data & Ver. 1.28 & 2005.06 \\
\hline \multirow{4}{*}{$\begin{array}{c}\text { Infrastructu } \\
\text { re }\end{array}$} & Reader Protocol & Ver. 1.1 & 2006.06 \\
\cline { 2 - 4 } & Reader Management & WD & - \\
\cline { 2 - 4 } & Tag Data Translation & Ver. 1.0 & 2006.01 \\
\hline \multirow{4}{*}{$\begin{array}{c}\text { Application Level } \\
\text { Exchange }\end{array}$} & Events(ALE) & Ver. 1.0 & 2005.09 \\
\cline { 2 - 4 } & EPCIS Capture Interface & WD & - \\
\cline { 2 - 4 } & EPCIS Data Specification & WD & - \\
\cline { 2 - 4 } & EPCIS Query Interface & WD & - \\
\cline { 2 - 4 } & EPCglobal Certificate Profile & Ver. 1.0 & 2005.10 \\
\hline & Ver. 1.0 & 2006.03 \\
\hline & EPCIS Discovery Service & $\begin{array}{c}\text { Research in } \\
\text { Business }\end{array}$ & - \\
\hline
\end{tabular}

\section{b) 국내 표준화 현황}

국내에서도 최근 국제표준으로 제정된 RFID용 프로토콜, 평가방법 등의 기술표준을 국가표준(KS)으로 도입하였다. 지식경제부 기술표준원은 $\mathrm{RFID}$ 의 국가적 산업화를 지원하 기 위해 $\mathrm{RFID}$ 성능기준 등 $\mathrm{RFID}$ 국가표준 $(\mathrm{KS})$ 을 제정하고 있다. 2005년부터 2008년까지는 RFID 태그 통신방식 등 산 업기반 분야의 국가표준 43 종(용어 2 종, 기반기술 9 종, 데이 터 11종, 시험 6종, 응용 15종)이 제정되어 산업·공공 확산 
사업 등에 적용 되어 왔고, 2008년에는 RFID 실행가이드라 인, $\mathrm{SCM}$ 응용 등 국가표준 $\mathrm{KS}$ ) 15종(용어 2종, 시험 1종, 응용 12종)을 제정하였다[9].

특히, 2009년에는 성능기준 및 시험 분야 5종, 소프트웨어 구조 등 데이터 분야 2종, 태그데이터 안전성 등 응용분야 3 종 등 국가표준 $(\mathrm{KS}) 10$ 종을 새로이 제정하였다[10].

Table 2. RFID standards enacted in 2009 (KS)

\begin{tabular}{|c|c|c|}
\hline $\begin{array}{c}\text { Classifi } \\
\text { cation }\end{array}$ & KS Standards & $\begin{array}{l}\text { International } \\
\text { Standards }\end{array}$ \\
\hline \multirow{3}{*}{ Test } & $\begin{array}{l}\text { Performance/Test Method(860 } 960 \mathrm{MHz} \text {, } \\
\text { 433MHz, 13.56MHz RFID system) }\end{array}$ & ISO 18046 \\
\hline & Test methods - System's performance & ISO $18046-1$ \\
\hline & Test methods - Reader's performance & ISO $18046-2$ \\
\hline \multirow{2}{*}{ Data } & Infrastructure for Software - Architecture & ISO $24791-1$ \\
\hline & Encoding \& processing for Sensor/Power & ISO 24753 \\
\hline \multirow{3}{*}{$\begin{array}{c}\text { Applica } \\
\text { tion }\end{array}$} & Implementation - The reliability of data & ISO $24729-4$ \\
\hline & Industry data - Product recognition & ISO 21849 \\
\hline & $\begin{array}{l}\text { Vehicle \& Equipment identification - } \\
\text { interface }\end{array}$ & ISO 17264 \\
\hline
\end{tabular}

\section{2 유관분야에서 국내·외 기술 동향}

물류산업에서 기존의 $\mathrm{SCM}$ 기술에 $\mathrm{RFID}$ 를 융합한 지능 형 $\mathrm{SCM}$ 의 기술이 대두되고 있는 가운데, 유관분야에서 현 재의 국내·외 기술 동향 및 수준에 대하여 살펴본다.

1) 국내 기술 동향 및 수준

우리나라는 RFID 산업 규격 단체인 EPCglobal로부터 $\mathrm{S} / \mathrm{W}$ 기술 적합성 인증을 다수 획득하였으나 고도화된 물류 정보 가시화 기술은 아직 초기 연구 단계에 있다. a) $\mathrm{RFID}$ 인프라관리 분야

원격 장치관리 및 모니터링 기능이 결합된 지능화된 $\mathrm{RFID}$ 장치 기술 개발이 $\mathrm{LG}$ 히다찌, 미네르바, ETRI, 유로지 스넷 등에서 추진되고 있으며, ETRI는 2007년부터 ISO/IEC 24791 표준화의 선임 에디터를 맡아 국제표준 기반 미들웨 어 플랫폼(SSI플랫폼11])을 개발 하였다.

b) 물류정보 네트워크 연계 분야

지식경제부는 RFID 기반의 차세대 지능형 물류시스템 개 발 사업의 일환으로 $\mathrm{URECA}$ (국내), UPLUS(유통), UGLP (국제)등을 추진하고 있으며, 관세청은 전자통관시스템 (UNI-PASS) 장애를 사전에 감지하여 예방할 수 있도록 수 출입통관 및 물류장애 조기경보시스템을 구축하였다. 또한 유로지스넷은 한국과 일본간 구축된 RFID기반 물류 데이터 동기화 기술 개발을 진행하고 있다.

c) 동기오류 검출 및 보정 분야

제조·물류-유통 기업을 중심으로 물류정보의 단순한 가 시화 시스템 개발 수준에 머물고 있다.

\section{2) 국외 기술 동향 및 수준}

$\mathrm{SSCM}$ 모델 개발과 동일하거나 유사한 제품 및 서비스는 현재 존재하지 않으나, RFID 기반 물류 인프라 원격제어 기 술 분야에 있어서는 Intermec에서 약 0.5 년의 기술격차를 두 고 앞서 있는 것으로 판단된다.

a) $\mathrm{RFID}$ 인프라관리 분야

Reva, Impinj, Intemec, Alien, Savi, Evigia, SAI 등 $\mathrm{RFID}$ 리더 장치 개발 기업에서 RFID 장치에 대한 원격 모 니터링 및 장치제어 기술 등의 지능형 $\mathrm{RFID}$ 시스템 연구를 진행하고 있으며, RFID 장치 원격관리 및 제어에 관련한 표

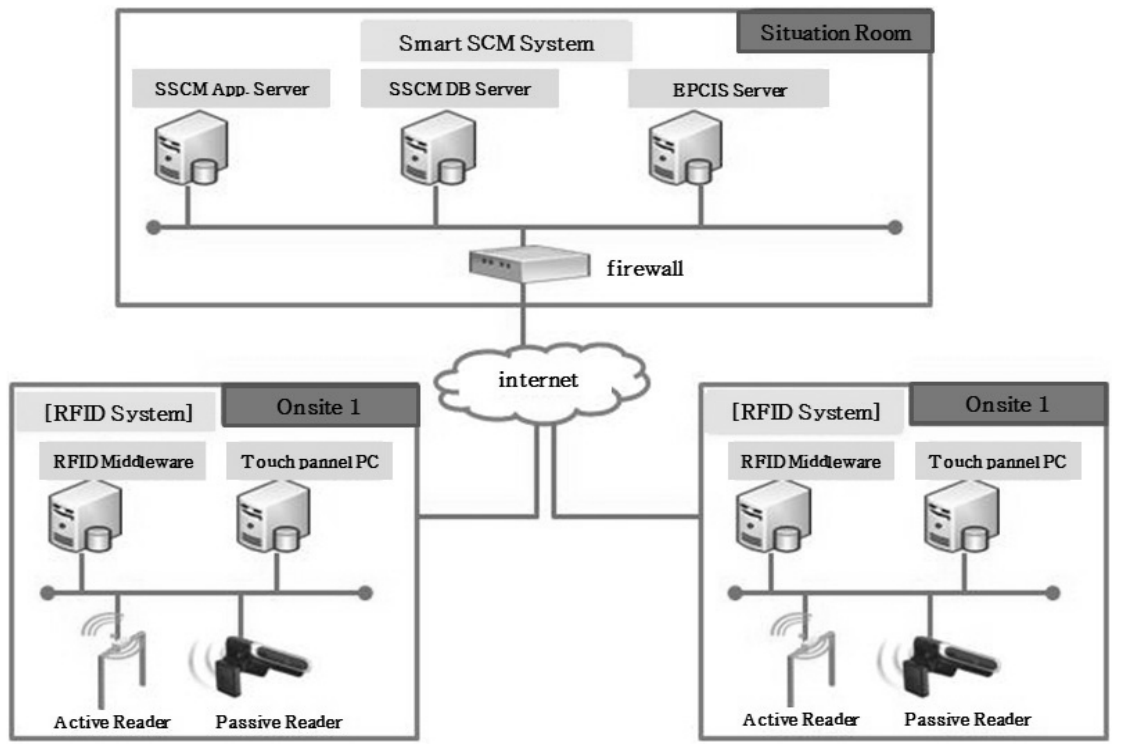

Fig. 1. Configuration of the SSCM system 


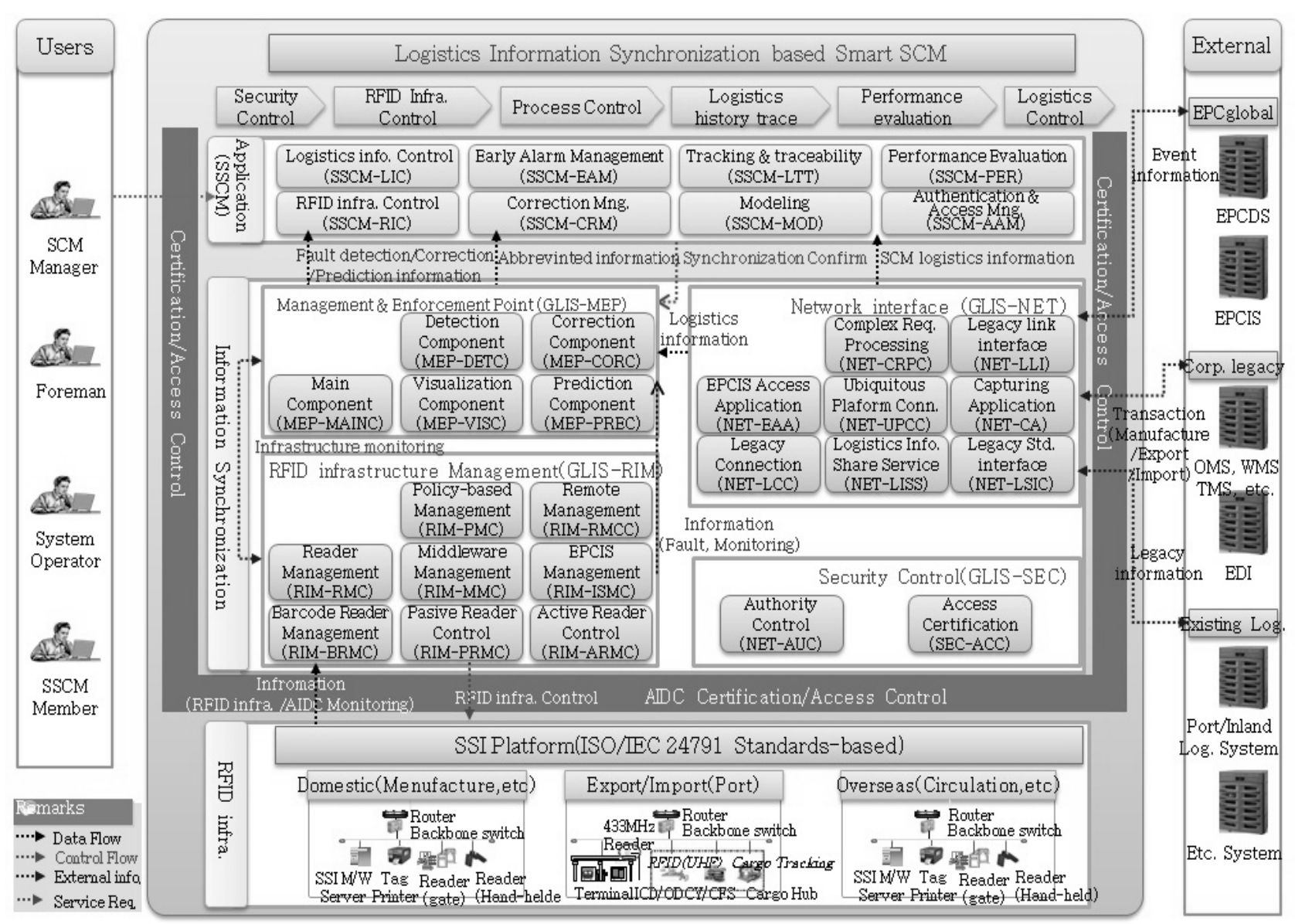

Fig. 2. Architecture of the SSCM system

준 인터페이스 규격이 EPCglobal과 ISO/IEC를 통해 개발되 고 있다.

b) 물류정보 네트워크 연계 분야

$\mathrm{GS} 1$ 의 GDSN은 인터넷을 기반으로 표준화되고 동기화된 상품정보를 교환하기 위한 네트워크를 구축하였으며, RFID 기반의 $\mathrm{EPC}$ 네트워크와의 상호 운영성을 추진하고 있으며, 일본은 경제산업성 주도하에 물류 및 IT 기업들은 동경에서 암스테르담까지 물류 거점 21곳에서 RFID 데이터를 수집하 는 검증을 수행하고 있다.

c) 동기오류 검출 및 보정 분야

GS1 유럽과 IBM, MS, HP, Alien, L'OREAL 등이 GTI 프로젝트에 참여하여 글로벌 물류 동기화 기술의 구축 및 종래 규격을 표준화하고 있다.

\section{3. 물류정보화 기반의 SSCM 모델 구축}

\subsection{SSCM의 Configuration}

본 연구에서 개발된 $\mathrm{SSCM}$ 시스템은 애플리케이션 서버, 데이터베이스 서버, EPCIS 서버 시스템으로 구성되며 현장
물류거점에서 재화의 흐름을 가시화하기 위한 $\mathrm{RFID}$ 시스템 과 데이터를 실시간으로 전송하기 위한 네트워크로 연결된다.

$\mathrm{SSCM}$ Application서버에는 RFID동기관리, RFID인프라 관리, 물류정보 연계, SSCM Dashboard 등 SSCM 시스템을 구성하는 주요 모듈이 탑재되며 실질적으로 사용자에게 서 비스를 제공하기 위한 웹서비스를 제공한다. SSCM DB서버 에는 개발 프로그램의 모든 관련 데이터들이 저장된다. 또 한, EPCglobal Network 구현을 위해 EPCIS 서버를 구축하 였으며 물류 거점에서 인식되는 모든 EPCIS 이벤트 데이터 들이 표준화된 방식으로 변환되어 저장된다. 물류 거점에 설치 운영되는 $\mathrm{RFID}$ 시스템은 $900 \mathrm{Mhz}$ 수동형 리더기, $433 \mathrm{Mhz}$ 능동형 리더기, RFID 미들웨어, 현장에서의 입·출 고 업무처리를 위한 터치패널 $\mathrm{PC}$ 로 구성되어, 공급망의 물 류현장에서 발생하는 데이터는 인터넷을 통해 실시간으로 데이터베이스 시스템에 전달된다.

\subsection{SSCM의 ToBe 모델}

1) 시스템의 기능 규격

$\mathrm{SSCM}$ 은 $\mathrm{RFID}$ 의 장치오류 감지 및 복구에 대한 문제 해 결 수요에 기반하여, 물류시스템간 연계를 하는 Horizontal 
Synchronization과 SCM 장비에서부터 개별 시스템으로 수 집되는 $\mathrm{SCM}$ 데이터를 모두 동기화하는 Vertical Synchronization를 가능케하는 공급망 통합관제 시스템이다. 또한, $\mathrm{SSCM}$ 은 $3 \mathrm{~A}$ (Accuracy, Assurance, Adaptivity) 기반 으로 실시간 공급망 관리 및 통제를 위한 그래픽 사용자 인 터페이스를 제공한다.

a) 공급망 모델링(SSCM-MOD)

- 공급망관리자가 공급망의 구성자원(거점, 품목, $\mathrm{RFID}$ 인프라, 운송경로 등)을 지도상에 등록 및 관리, 거래정보를 기반으로 각 거점별로 처리되는 물류 프로세스의 설계

b) RFID 인프라 관제(SSCM-RIC)

- 각 거점의 $\mathrm{RFID}$ 인프라 상황 모니터링 및 장애발생시 알람 및 메시지 제공, $\mathrm{RFID}$ 인프라 장애 조치내역 제공

c) 물류정보 동기관제(SSCM-LIC)

- 물류프로세스에 대한 상태정보 제공 및 Infra Service 를 통하여 $\mathrm{EPCIS}$ 서버의 보정된 재고수량 취득, 물류정보 동기오류 보정처리 결과 제공

\section{d) 물류정 조기경보(SSCM-EAM)}

- GLIS-MEP로부터 조기경보 수신 및 SSCM내에서 조 기경보 및 오류보정 처리 결과를 인터페이스

e) 물류정보 동기오류 보정처리(SSCM-COR)

- 물류정보 동기오류 보정 계획을 수집, 공급망관리자에 게 오류 처리를 위한 지원, 정보 제공, 오류사항 처리 및 결 과 입력

f) 공급망 물류이력 추적(SSCM-LTT)

- 개별 물품수준의 현재 위치 및 물류 이동 이력에 대 한 이력추적 정보 제공

g) 공급망 성능평가(SSCM-PER)

- 기술적 모니터링 레포트, 주요 성능지표(KPI)의 생성

h) RFID인프라 실시간 원격관리(GLIS-RIM)

- 원격 $\mathrm{N} / \mathrm{W}$ 에 연결된 RFID인프라의 동작 및 네트워크 연결 상태 모니터링, 장애 정책과 규칙에 따른 자율 복구

i) 개방형 네트워크 연계(GLIS-NET)

- SCM상의 $\mathrm{EPCIS}$ 간 물류정보의 동기화 및 개방형 물 류정보 관리, $\mathrm{EDI}$ 데이터 공유 및 다자간 Business Intelligence 정보 공유 서비스

j) 동기오류 검출 및 보정(GLIS-MEP)

- 네트웍상에서 전달되는 정보보호를 위한 다자간 물류 정보 접근제어, 물류정보 동기오류 검출·보정 및 유형분석 k) 물류정보 보안관리(GLIS-SEC)

- 기반체계 내의 모든 서브시스템및 $\mathrm{SSCM}$ 시스템의 보 안을 통제

\section{2) $\mathrm{SSCM}$ 의 Dashboard}

$\mathrm{SSCM}$ 시스템은 Dashboard 형태로 구성한다. 본 화면을 통하여 SSCM 사용자는 RFID인프라 및 물류 프로세스 현황 을 통합하여 모니터링이 가능하며, 예외상황 발생 시 문제해 결을 위하여 즉각적인 의사결정을 지원하는 다양한 정보의 분석이 가능한 공급망 통합관제 시스템으로 구성하였다.

\section{a) 물류 통합관제}

물류 통합관제 화면은 지도상에 물류거점별로 설치 운영 되는 $\mathrm{RFID}$ 인프라 장치의 동작 상태를 표현한다. 또한, 발주 서에 해당하는 물품의 현재 운송되는 위치를 모니터링 한다.

b) $\mathrm{RFID}$ 인프라 통합관제

$\mathrm{RFID}$ 인프라 통합관제 화면의 주요 기능은 첫째, 공급망 또는 발주서별로 현재 상품의 물리적인 위치와 현재 물류업 무(입출고, 포장 등)의 단계를 알려주고 물류정보에 대한 동 기 오류 상태를 표시한다. 둘째, 비즈니스 프로세스 모니터 링 기능으로 발주서 물류정보 동기오류 상태를 확인할 수 있으며 해당 물류의 과거 - 현재 - 미래의 위치와 프로세스를 파악할 수 있다. 셋째, 발주서 별로 물류정보의 동기오류 및 $\mathrm{RFID}$ 인프라 장치의 상세 이력정보를 제공한다. 또한 기간 별, 거점별 물류오류 및 RFID 인프라 오류 추세를 그래프를 통해 표시한다.

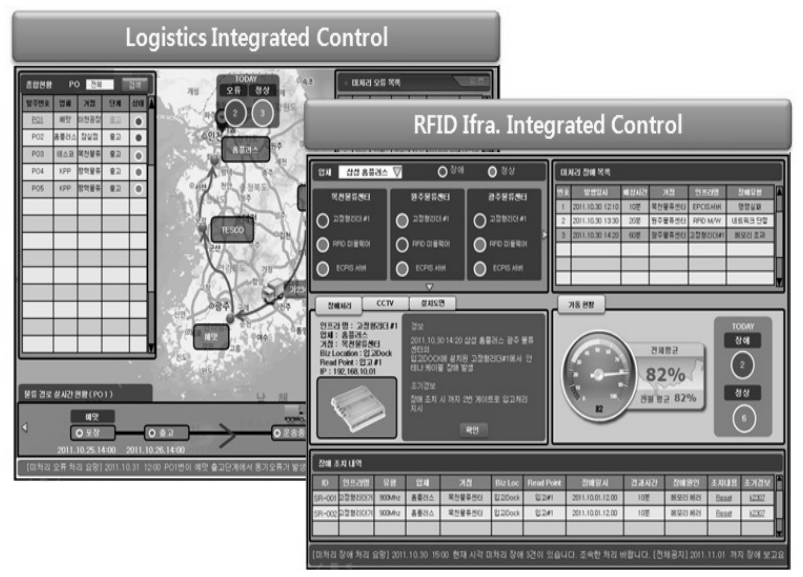

Fig. 3. Control screen of the SSCM system

\section{SSCM 모델의 적용분야}

산업전반에 걸쳐 생산기지가 다양화되고 글로벌 소싱을 확대하면서, 업체간 협업을 위한 물류전반에 걸쳐 즉, 국내 내륙(제조, 물류, 유통), 수입 - 수출(항만), 해외내륙(물류, 유 통 물류에 $\mathrm{SSSCM}$ 의 적용이 가능하다. 본 장에서는 수출산 업의 SSCM 모델 적용에 대하여 기술한다. 


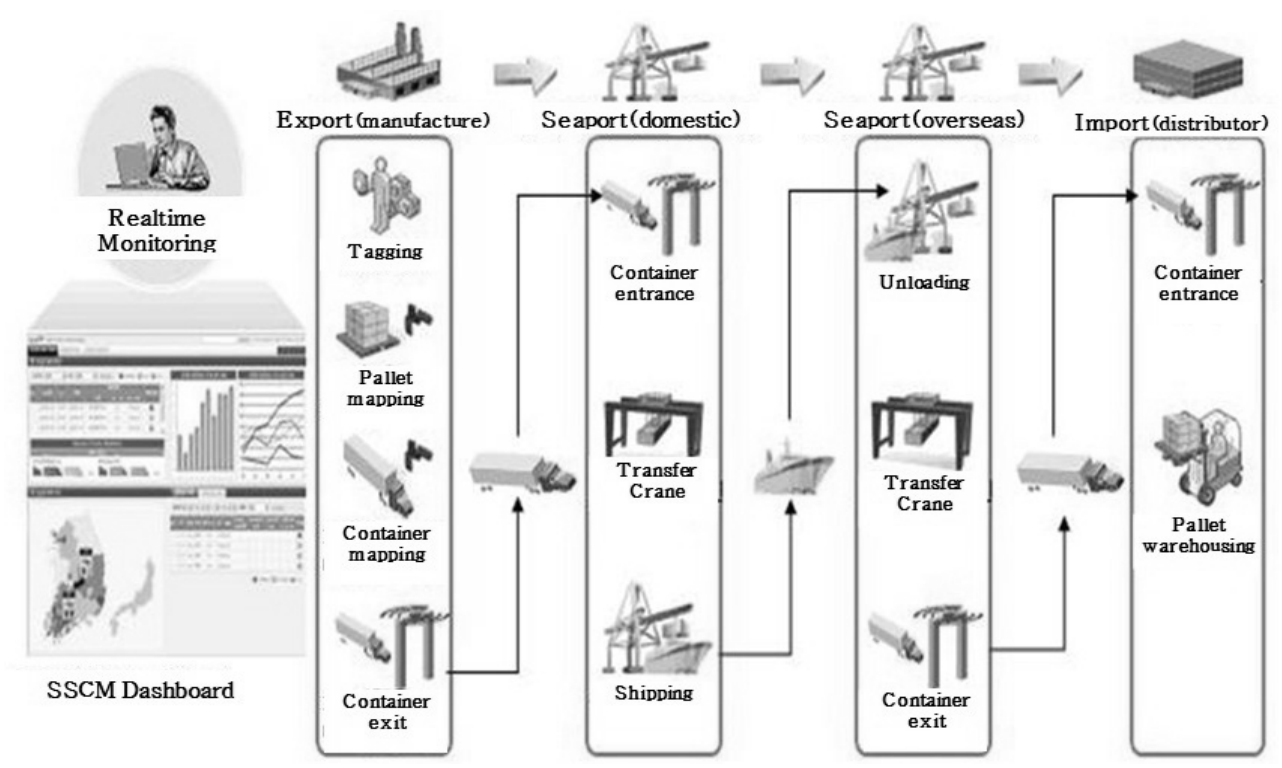

Fig. 4. SSCM model of export industries

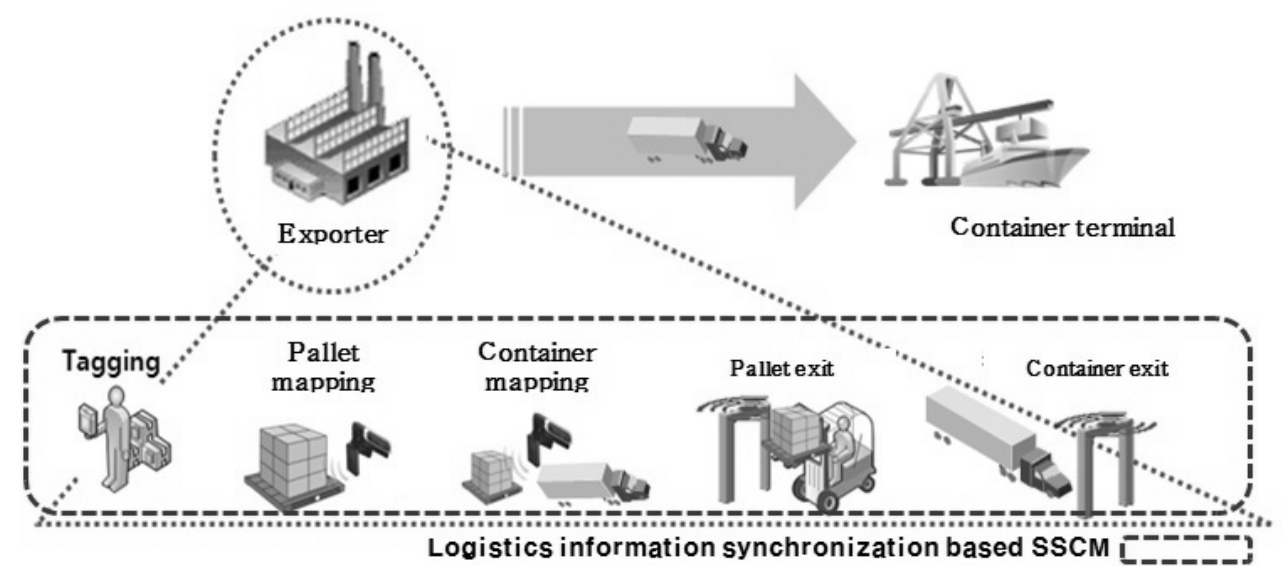

Fig. 5. Reader points of the RFID for Logistics

4.1 수출산업에서의 SSCM 모델 적용

수출산업에서 주요한 물류 처리 업무프로세스는 크게 선 박 입·출항, 운송, 화물운송, 화물 반 - 출입, 화물보관, 사후 관리 등으로 나눌 수 있다. 수출물류 프로세스 상에 SSCM 시스템을 적용하여 여러 기업이 연관된 공급 - 유통 - 물류 · 판매·소비·회수 전반에 이르는 End-To-End 공급망 상에 서 정보의 단절이나 오류 없이 개별물품 수준의 실시간 정 보 관리를 지속적으로 운용할 수 있다. 또한, 권한을 가진 사용자는 $\mathrm{SSCM}$ 시스템을 통하여 발주에서 시작되는 물류 전과정을 실시간으로 원격 감시하여 RFID 인프라의 장애 또는 이상 상태에 의해 발생한 물류정보의 오류를 조기에 감지하고 보정 및 복구를 자율적으로 수행하는 서비스를 제 공할 수 있다.

4.2 물류 프로세스에서 적용 분야별 표준 $\mathrm{RFID}$ 의 적용 분야별 표준은 다음과 같다.
Table 3. Applicability objects

\begin{tabular}{|c|l|c|}
\hline Objects & \multicolumn{2}{|c|}{ Contents } \\
\hline \multirow{2}{*}{ Packing } & Name & ISO/TC122(Boxing, Packing) \\
\cline { 2 - 4 } & Range & International standards of packaging sector \\
\hline \multirow{2}{*}{ Pallet } & Name & ISO/TC51(For the transport) \\
\cline { 2 - 4 } & Range & $\begin{array}{c}\text { Pedestal that can be packaged in the form } \\
\text { of unit load }\end{array}$ \\
\hline \multirow{2}{*}{ Container } & Name & ISO/TC104(Cargo container) \\
\cline { 2 - 4 } & Range & Cotainer with a capacity of more than 35.3ft \\
\hline \multirow{2}{*}{ Forklift } & Name & ISO/TC110(Industrial trucks) \\
\cline { 2 - 4 } & Range & Power-operated/Manual forklift \\
\hline \multirow{2}{*}{ Barcode } & Name & ISO/IEC JTC1/SC31(Barcode symbol) \\
\cline { 2 - 4 } & Range & Recognized standard for data collection \\
\hline
\end{tabular}




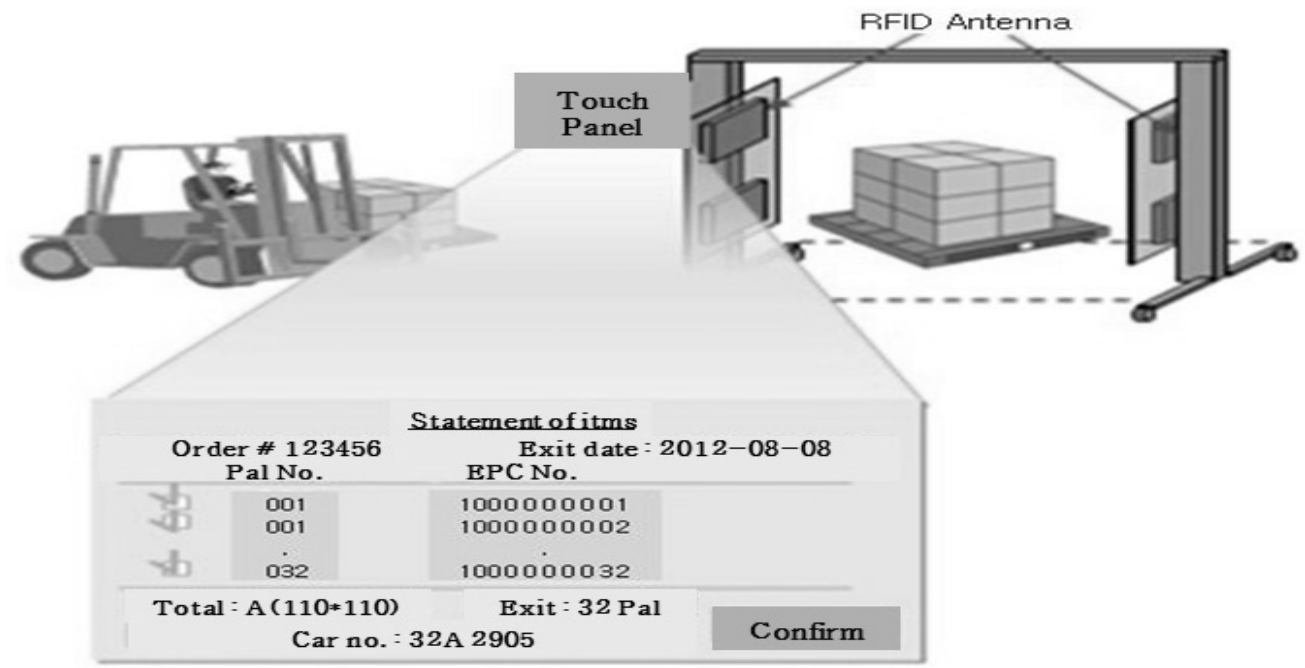

Fig. 6. RFID fixed gate and the touch panel

4.3 Location별 물류정보 동기화 기술 적용 포인트

1) 국내 수출 제조업체

수출제조업체에 SSCM시스템 기술을 적용하기 위한 $\mathrm{RFID}$ 리더의 설치 포인트는 아래와 같다.

파렛트 출고 작업자는 RFID 고정형 게이트 통과시 터치 패널 상에 출고 정보를 선택하고 출고 작업을 시작한다.

또한 사용자는 $\mathrm{SSCM}$ 시스템으로 물류 프로세스를 실시간 으로 모니터링하여 출고작업 중에 거점에 설치된 $\mathrm{RFID}$ 장 비의 장애에 의해 발생한 정보 불일치 현상을 감지하여 자 율적 또는 비자율적으로 보정 및 복구를 수행한다.

\section{2) 컨테이너 터미널(국내항만)}

컨테이너에 $433 \mathrm{MHz}$ 의 RFID 태그를 부착하여 제조업체, 국내 항만 입 - 출문 정보를 $\mathrm{RFID}$ 리더를 통하여 실시간으 로 자동관리 하도록 하기 위하여 컨테이너가 입 - 출차하는 곳에 $\mathrm{SSCM}$ 기술 기반의 RFID 인프라 장비를 설치하여 물 류정보 모니터링 서비스를 제공한다.

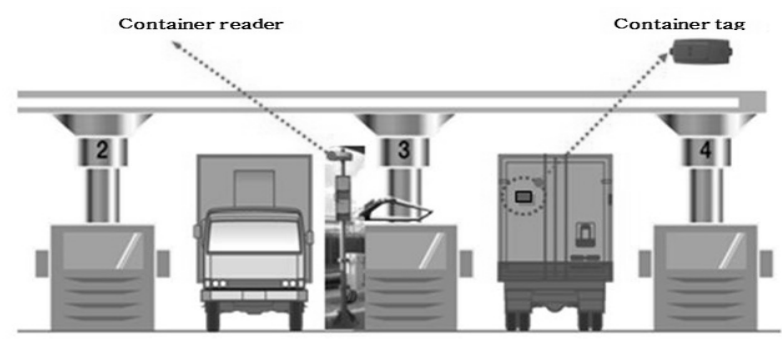

Fig. 7. Location of the RFID reader in container terminal

\section{5. 결론 및 향후 연구 과제}

본 논문에서 구축한 $\mathrm{SSCM}$ 모델은 현장 서비스 적용을 위 하여 $\mathrm{KPP}, \mathrm{LG}$ 생활건강 등 대형 물류센터를 실사하여 현장
의 니즈를 시스템 프로세스에 반영하였으며, 물류국제 표준, $\mathrm{RFID}$ 관련 국제 표준 규격, $\mathrm{EPCIS}$ 표준, SSI 미들웨어 플랫 폼을 준용하여 표준화 하므로써 관련 기술 국내 표준 규격 을 제시하고자 하였다.

$\mathrm{SSCM}$ 모델은 글로벌 환경에서의 RFID 인프라 관리의 한 계를 극복하고 RFID 인프라 설치·운용상의 어려움 및 유지 보수 비용을 대폭 절감하는 한편, 물류정보의 실시간 Visibility와 Traceability를 확보함으로써 기존 RFID 기반 물류 서비스의 신뢰성을 향상시킬 수 있다. 또한, 기술 개발 및 시장 진입 초기 단계인 $\mathrm{RFID}$ 기반 Smart SCM 기술의 조기 확보를 통해 국내 기업의 해외 시장 경쟁력과 기술 수 출입 대체 효과를 기대할 수 있지만, RFID 설비영역의 완벽 한 인식율 제고를 위한 기술적인 진보와 글로벌 물류산업의 추진을 위한 $\mathrm{SCM}$ 시스템을 독자적으로 구축하기 어려운 국내·외의 영세한 중소기업에게 클라우드 컴퓨팅 서비스를 목표로 점진적 고도화를 통하여 현장적용이 가능한 표준형 $\mathrm{SSCM}$ 으로의 실증연구가 필요하다.

\section{참 고 문 헌}

[1] IPA, "To take advantage of RFID in SCM", The Korea Economic Daily, pp.14-28, 2009.

[2] T.W. Ahn, "A Study on the RFID Applications for the Boned Logistics process", DongEui University, $\mathrm{PhD}$ thesis, pp.24-35, 2010.

[3] http://www.mightcard.co.jp/, 2008.09

[4] EPCglobal, "Discovery, Configuration, and Initialization(DCI) for Reader Operations 1.0”, EPCglobal Inc, 2009.

[5] EPCglobal, "The Application Level Events(ALE) Specification, 1.1, Part I: Core Specification”, EPCglobal Inc, 2008.

[6] SO/IEC JTC1, "ISO/IEC FDIS(Final Draft International Standard) 24791-1", ISO/IEC, 2010. 
[7] J.M. Ahn, et al, "The Utilization of RFID technology based on EPCglobal Network", Global, pp.58-64, 2007.

[8] S.W. OH, et al, "RFID Technology Standardization Trends", ETRI, Electronics and Telecommunications Trends, Vol.25, No.4, pp.6-7, 2010.

[9] MKE, "Enactment of 17 kinds of national standards for RFID diffusion”, KATS Press release, pp.1-4, 2008. 5. 22.

[10] MKE, "Expansion of the national standards for RFID diffusion”, KATS Press release, pp.1-3, 2009. 4. 30.

[11] ETRI, "Next-Generation middleware the 'SSI Plaform' development", Press No.2010-87, pp.1-4, 2010. 12.

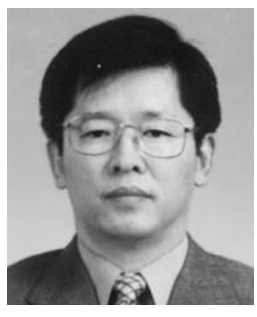

김 장 군

e-mail : legend7080@gmail.com 2008년 한성대학교 경영학(석사) 2012년 한세대학교(공학박사)

1986년 현 재 $\mathrm{LG}$ 히다찌 솔루션사업본부

관심분야: IT융합, 정보보호, SW공학 